\title{
ESTUDO DE SECAGEM E CARACTERIZAÇÃO DE RESÍDUO DE BATATA
}

\author{
C. M. FERREIRA e M. T. B. PERAZZINI
}

Universidade Federal de Itajubá, Instituto de Recursos Naturais

E-mail para contato: carolinamachadof10@unifei.edu.br

\begin{abstract}
RESUMO - Na indústria de processamento de batata, os produtos mais comercializados são as batatas palha e chips e como em todo processo, grandes quantidades de resíduos são geradas diariamente, como a casca de batata. Uma alternativa de tratamento deste resíduo, a fim de diminuir o impacto ambiental causado pelo seu descarte inadequado é a técnica de secagem. Os experimentos de secagem foram conduzidos para espessuras de 0,5 e $1,0 \mathrm{~cm}$ e temperaturas de 60 e $70^{\circ} \mathrm{C}$. Realizou-se ainda caracterização físico-química e termofísica do resíduo in natura e após o processo de secagem. Os resultados obtidos mostraram que o resíduo apresenta um elevado conteúdo de umidade inicial, o que favorece a sua deterioração. Os experimentos de secagem mostraram ainda que tanto a espessura do resíduo quanto a temperatura influenciam o processo, no entanto, a temperatura exerceu efeito mais significativo. A caracterização do resíduo mostrou que este apresenta um potencial energético elevado e que a condutividade térmica é favorecida pelo resíduo in natura.
\end{abstract}

\section{INTRODUÇÃO}

A batata (Solanum tuberosum L.) é o quarto produto agrícola mais consumido e cultivado no mundo (Resende, 2010). No cenário brasileiro a hortaliça apresenta grande importância, sua produtividade está em ascensão, visto o aumento tanto do consumo in natura quanto dos processados. Atualmente o maior estado produtor do Sudeste é Minas Gerais, tendo o Sul de Minas a maior área de plantio (Agrianual, 2015). Todavia o país ainda importa de vários países, tendo, portanto muito a ser desenvolvido neste setor a fim de buscar a sua autossuficiência (Andreatta, 2016).

No Brasil, como no mundo, a indústria da batata é uma indústria em expansão, devido à versatilidade e composição de seus produtos. Dentre os produtos existentes incluem-se os congelados e desidratados, mas são as batatas desidratadas palha e chips que são mais comercializadas (Carvalho, 2012).Como todo processo industrial, a fabricação de batatas palha e chips gera grandes quantidades de resíduos, sendo estes a casca da batata, polpa residual da batata e o amido. De acordo com Fernandes et al. (2008), no Brasil cerca de 300 mil toneladas de casca de batata são descartas anualmente. A formação de resíduos sólidos é um grande problema ambiental nos dias atuais, e para gerenciar melhor essa produção e tentar amenizar o impacto ambiental foi sancionada pela Lei $\mathrm{n}^{\circ}$ 12.305/2010 a Política Nacional dos Resíduos Sólidos - PNRS (Ministério do Meio Ambiente, 2016). 
Uma alternativa de tratamento do resíduo de casca de batata é técnica de secagem. A secagem promove a remoção de umidade de um material para a formação de um produto com baixa umidade. Este processo contribui para a conservação do produto, uma vez que, os microrganismos, que degradam a matéria orgânica, ficam incapazes de se reproduzir e crescer e várias enzimas, que promovem reações químicas, ficam inativadas (Geankoplis, 2014). Este autor ainda ressalta que além de preservar o produto por muito mais tempo, a secagem é um método que aumenta a versatilidade do material e reduz seu volume e peso, facilitando o transporte, armazenamento e manuseio. Assim, o objetivo desse trabalho foi realizar o tratamento térmico da casca de batata, bem como avaliar as características do material in natura e após a secagem. De posse destas informações, pretende-se obter um produto de valor agregado, evitando desse modo o descarte inadequado deste resíduo no meio ambiente.

\section{MATERIAIS E MÉTODOS}

\subsection{Resíduo Orgânico}

A casca de batata utilizada para os ensaios experimentais, mostrada na Figura 1,foi gerada no processo de produção de Batata Suprema palha e chips, fornecida pela empresa Casa Mineira de Batatas localizada em Maria da Fé-MG. Selecionou-se a casca de batata, uma vez que, os demais resíduos produzidos pela empresa já possuem um destino; a polpa residual é vendida para a fabricação de ração animal e o amido é vendido para a produção de cola.

Figura 1 - Resíduo de casca de batata in natura

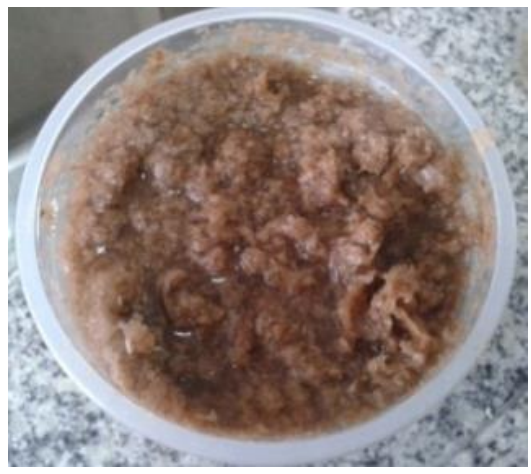

Fonte: Pessoal (2017)

\subsection{Procedimento Experimental}

Secagem do resíduo: O secador utilizado neste trabalho é composto por um soprador, resistência elétrica e um túnel de vento com 1,0 m de comprimento e 13,8 cm de diâmetro. A amostra era posicionada a uma altura de $5,0 \mathrm{~cm}$ da base do tubo. Um esquema da unidade de secagem utilizada neste trabalho é apresentado na Figura 2.

Para realizar a secagem do resíduo, verificou-se a necessidade de retirar o excesso de umidade presente na amostra. Para isso, pressionou-se a amostra em uma peneira com o auxílio de um vidro de relógio. Em seguida, a placa de petri com diferentes espessuras de resíduo $(0,5$ e $1,0 \mathrm{~cm})$ foi inserida na câmara de secagem. Inicialmente, a amostra foi pesada em intervalos de $10 \mathrm{~min}$, quando o intervalo de decaimento da massa começou a ser pequeno, 
a pesagem da amostra foi realizada em intervalos de $30 \mathrm{~min}$. Assim que a massa da amostra passou a ser constante, a mesma foi retirada do secador e levada para estuda por $24 \mathrm{~h}$ a $105^{\circ} \mathrm{C}$. Os experimentos foram conduzidos para temperaturas do ar de secagem de 60 e $70^{\circ} \mathrm{C}$.

Figura 2 - Esquema da unidade experimental de secagem: (1) soprador, (2) resistência elétrica, (3) túnel de vento, (4) termômetro de mercúrio e (5) amostra

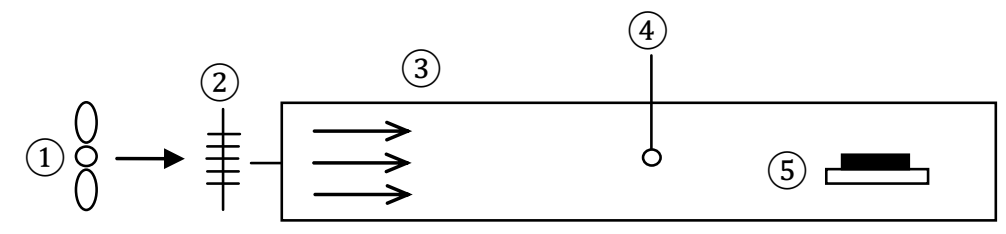

Fonte: Pessoal (2017)

Caracterização do resíduo: A caracterização do resíduo in natura e após a secagem consistiu na determinação da massa específica do material e do meio (densidade bulk) pelos métodos de picnometria e gravimetria. $\mathrm{O} \mathrm{pH}$ e acidez titulável foram determinados seguindo as normas analíticas do Instituto Adolfo Lutz (2008). O PCS foi obtido pelo ensaio na bomba calorimétrica e por fim, a condutividade térmica obtida pelo método da sonda linear.

\section{RESULTADOS E DISCUSSÕES}

\subsection{Caracterização do Resíduo}

Na Tabela 1 são apresentados os resultados obtidos por meio da caracterização físicoquímica e termofísica da casca de batata in natura e após o processo de secagem.

Tabela 1 - Caracterização do resíduo in natura e seco

\begin{tabular}{|c|c|c|}
\hline & Resíduo Úmido & Resíduo Seco \\
\hline Umidade $(\%)$ & 90,27 & - \\
\hline$\rho\left(\mathrm{kg} / \mathrm{m}^{3}\right)$ & 1032,4729 & 111,6536 \\
\hline$\rho_{\mathrm{m}}\left(\mathrm{kg} / \mathrm{m}^{3}\right)$ & 941,3333 & 77,3333 \\
\hline$\varepsilon_{\mathrm{m}}$ & 0,0884 & 0,3106 \\
\hline $\mathrm{pH}$ & $5,9 \pm 0,1$ & $5,22 \pm 0,08$ \\
\hline Acidez Titulável $(\% \mathrm{v} / \mathrm{m})$ & $0,016 \pm 0,004$ & $0,05 \pm 0,01$ \\
\hline $\mathrm{k}\left(\mathrm{W} / \mathrm{m}^{\circ} \mathrm{C}\right)$ & 0,1385 & 0,0169 \\
\hline $\mathrm{PCS}(\mathrm{J} / \mathrm{g})$ & - & 19375 \\
\hline
\end{tabular}

Fonte: Pessoal (2017)

Conforme os dados apresentados na Tabela 1 verificou-se que o resíduo estudado apresenta um elevado conteúdo de umidade, em média 90,27\%, o que favorece a sua deterioração tanto físico-química como microbiológica. Os resíduos in natura e após o processo de secagem apresentaram em média um $\mathrm{pH}$ de 5,90 e 5,22, respectivamente. Estes resultados mostram que a casca de batata apresenta característica levemente ácida, já a batata (tubérculo) apresenta menor acidez com um pH acima de 6,0(Virmond et al., 2014).É 
importante ressaltar, que o $\mathrm{pH}$ do resíduo pode variar muito pois depende da qualidade da batata, temperatura e processos fermentativos. Isto pode ser verificado nos trabalhos de Santos (2013) na qual constatou um pH para casca de batata de 3,50 e Azeitona (2012) que obteve um $\mathrm{pH}$ de 5,90 $\pm 0,61$. Com relação à acidez titulável foi obtido um valor de $0,016 \pm$ $0,004 \%(\mathrm{v} / \mathrm{m})$ para o resíduo úmido e $0,05 \pm 0,01 \%(\mathrm{v} / \mathrm{m})$ para o resíduo seco. Esses resultados mostraram-se condizentes com os resultados do $\mathrm{pH}$, já que $\mathrm{pH}$ e acidez são inversamente proporcionais. O PCS apresentou um valor de $19375 \mathrm{~J} / \mathrm{g}$ mostrando que a casca de batata apresenta grande potencial energético, uma vez que grandes fontes de energia renovável como a biomassa do bagaço de cana e casca de arroz apresentam um PCS de 18312 J/g e 16747,2 J/g, respectivamente (Silva e Moraes, 2008; Diniz et al., 2004). Verificou-se ainda que a condutividade térmica foi maior para o resíduo in natura, mostrando que a condutividade térmica aumenta com o aumento da umidade e com a diminuição da porosidade.

\subsection{Cinética de Secagem}

As Figuras 3(a) e 3(b) mostram o comportamento das curvas de cinética de secagem e taxa de secagem para $0,5 \mathrm{~cm}$ de espessura e resíduo e temperatura de $60^{\circ} \mathrm{C}$.

Figura 3 - Secagem do resíduo para 0,5cm de espessura e $60^{\circ} \mathrm{C}$ : (a) Dados de umidade adimensional em função do tempo e (b) Taxa de secagem.
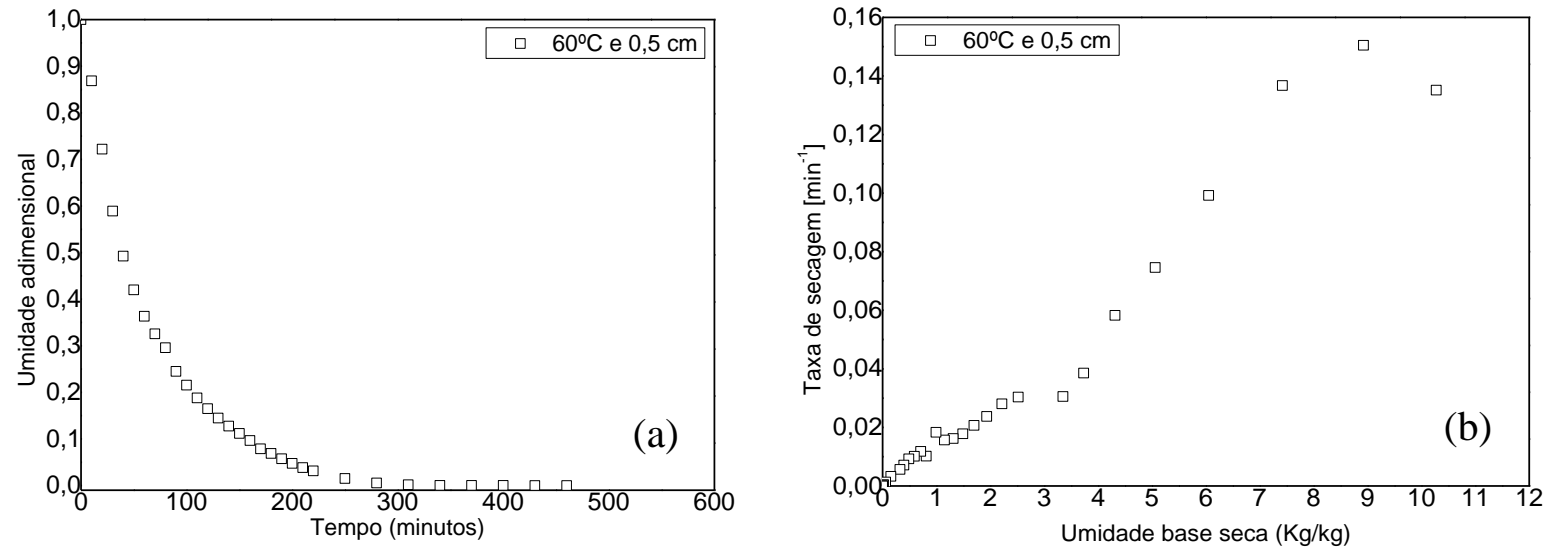

Fonte: Pessoal (2017)

Conforme mostra a Figura 3(a), o processo de secagem da casca de batata é constituído basicamente pelo período de secagem a taxa decrescente, no qual indica que a água da superfície do resíduo é insuficiente para manter o filme contínuo em sua superfície. Observando a Figura 3(b), é possível confirmar o curto tempo da taxa de secagem constante, comprovando o que Foust et al. (2013) afirma sobre materiais orgânicos. Estes resultados reafirmam que a maior parte do processo é comandada pelo sólido e que o fluxo de ar não exerce grande influência na eficiência do método. Comportamento semelhante foi observado para as demais condições operacionais estudadas.

Estudou-se ainda a influência da temperatura e da espessura de resíduo no processo de secagem da casca de batata, conforme mostram as Figuras 4(a) e 4(b). 
Figura 4 - Dados de umidade adimensional em função do tempo: (a) $0,5 \mathrm{~cm}$ de espessura e diferentes temperaturas: $60^{\circ} \mathrm{C}$ e $70^{\circ} \mathrm{C}$ e (b) $70^{\circ} \mathrm{C}$ e diferentes espessuras: $0,5 \mathrm{~cm}$ e $1,0 \mathrm{~cm}$
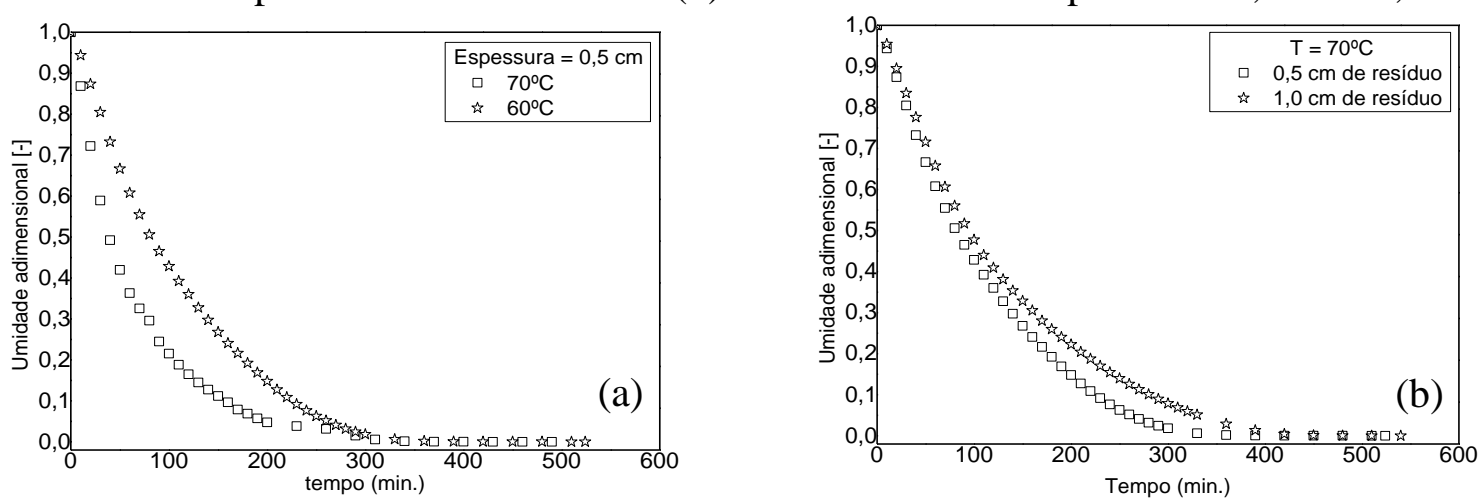

Fonte: Pessoal (2017)

Os dados apresentados na Figura 4 (a) apresentaram uma discrepância entre os valores de temperatura estudados. Isto mostra que a temperatura é uma variável importante e que esta exerce influência no processo de secagem da casca de batata. Estes dados mostram ainda que a elevação da temperatura do ar utilizado para secagem favoreceu a transferência de massa requerendo desta forma, um menor tempo para a secagem do resíduo estudado. Os resultados obtidos estão coerentes com os trabalhos de Silva et al. (2009) e Lopes (2013).

Conforme os dados apresentados na Figura 4(b) constatou-se que a espessura também exerceu efeito no processo de secagem do resíduo, uma vez que, o aumento da espessura elevou o tempo necessário para a secagem da amostra. Isto porque, quanto maior a camada de resíduo utilizada maior será a dificuldade da água presente no interior da amostra migrar até a superfície. Resultados similares foram observados por Silva et al. (2009).Os resultados obtidos mostraram que, para as condições operacionais avaliadas neste trabalho, a temperatura apresentou efeito mais significativo quando comparada ao efeito da espessura de resíduo no processo de secagem da casca de batata. Observou-se ainda neste trabalho que, a secagem de um material orgânico não pode ser generalizada, visto que estes apresentam características intrínsecas e que podem sofrer modificações antes e durante o processo de secagem. No caso da secagem da casca de batata, as condições ambientais, tal como umidade e temperatura do ar ambiente, as condições do resíduo como: estágio no processo de degradação fermentativa, conteúdo de umidade inicial, espécie da batata utilizada, são fatores que podem interferir no processo de secagem deste tipo de material. Além disso, estes fatores dificultam manter as mesmas características do resíduo em todos os procedimentos experimentais, o que mostra o quanto a secagem de resíduos de origem orgânica é desafiadora.

\section{CONCLUSÃO}

No presente trabalho estudou-se a da influência da temperatura e da espessura da amostra no processo de secagem de casca de batata em secador de leito fixo, bem como a caracterização físico-química e termofísica do resíduo. Os experimentos de secagem mostraram que a temperatura e a espessura do resíduo são variáveis de grande influência no processo de secagem, sendo a temperatura a variável com maior interferência. Conclui-se ainda que as condições ambientais, o tempo de armazenamento do resíduo, bem como, fatores metabólicos são fatores importantes que devem ser estudados no processo de secagem da 
casca de batata. A caracterização do resíduo mostrou que a casca de batata apresenta um grande potencial energético e condutividade térmica é mais evidenciada no resíduo in natura.

\section{NOMENCLATURA}

$\begin{array}{lll}\mathrm{k} & \text { Condutividade térmica } & {\left[\mathrm{W} / \mathrm{m}^{\circ} \mathrm{C}\right]} \\ \mathrm{m} & \text { Massa } & {[\mathrm{ml}]} \\ \mathrm{PCS} & \text { Poder calorífico superior } & {[\mathrm{J} / \mathrm{g}]} \\ \mathrm{v} & \text { Volume } & {[\mathrm{ml}]} \\ \varepsilon_{\mathrm{m}} & \text { Porosidade do meio poroso } & {[-]} \\ \rho & \text { Massa específica aparente do sólido } & {\left[\mathrm{kg} / \mathrm{m}^{3}\right]} \\ \rho_{\mathrm{m}} & \text { Massa específica do meio } & {\left[\mathrm{kg} / \mathrm{m}^{3}\right]}\end{array}$

\section{REFERÊNCIAS}

AGRIANUAL. Anuário da Agricultura Brasileira.São Paulo: FNP, 2015, 512p.

ANDREATTA, A. Importações Brasileiras de Sementes de Batata: Uma perspectiva do que ocorreu no setor nos últimos dez anos. Disponível em: <http://www.abbabatatabrasileira.com.br/revista16_017.htm>. Acesso em: 12 ago. 2016.

CARVALHO, W. T. de. Secagem de Polpa Residual Obtida na Industrialização de Batata Frita. 2012. 118 f. Dissertação (Mestrado) - Curso de Engenharia de Alimentos, Universidade Federal de Goiás, Goiânia, 2012.

FERNANDES, A. F. et al. Efeito da substituição parcial da farinha de trigo por farinha de casca de batata (Solanum tuberosum Lineu). In: Ciência e Tecnologia de Alimentos, 2008, Campinas. p. 56 - 65.

FOUST, A. S. et al. Princípios das Operações Unitárias.2. ed.Rio de Janeiro: Ltc, 2013.

GEANKOPLIS, C. J. Transport Processes and Separation Process Principles. 4. ed. Westford: Prentice Hall, 2014.

Instituto Adolfo Lutz. Métodos físico-químicos para análise de alimentos.4. ed. São Paulo: IAL, 2008. p. 103-106.

LOPES, F. J. Estudo do fenômeno de encolhimento na secagem convectiva de abacaxi com aplicação de micro-ondas. 2013. Dissertação (Mestrado) - Centro de Ciências e Tecnologias Agropecuárias, Universidade Estadual do Norte Fluminense, Campos dos Goytacazes, 2013.

Ministério do Meio Ambiente. Política Nacional de Resíduos Sólidos. Disponível em: <http://www.mma.gov.br/política-de-resíduos-sólidos>. Acesso em: 16 ago. 2016.

RESENDE, D. S. de. Caracterização de resíduos sólidos de estação de tratamento de esgoto da indústria de batatas e avaliação como adição para a produção de compósitos cimentícios. 2010. 117 f. Dissertação (Mestrado) - Curso de Engenharia de Materiais, Universidade Federal de Ouro Preto, Ouro Preto, 2010.

SILVA, A. S.; MELO, K. dos S.; ALVES, N. M. C.; GOMES, J. P. Cinética de secagem em camada fina de banana maça em secador de leito fixo. In: Revista de Biologia e Ciências da Terra, 2009, v. 9, n. 2, p. 107- 115.

SILVA, M. B. da; MORAIS, A. dos S. Avaliação Energética do Bagaço de Cana em Diferentes Níveis de Umidade e Graus de Compactação. In: XXVIII Encontro Nacional de Engenharia de Produção, 2008, Rio de Janeiro. 